\title{
Structural refinement of neutron powder diffraction data of two-stage martensitic phase transformations in $\mathrm{Ti}_{50.75} \mathrm{Ni}_{47.75} \mathrm{Fe}_{1.50}$ shape memory alloy
}

\author{
Husin Sitepu ${ }^{\text {a) }}$ \\ Crystallography Laboratory, Virginia Tech, Blacksburg, Virginia 24061, USA and Prince Sultan University, \\ P.O. Box 66833, Riyadh 11586, Saudi Arabia
}

(Received 21 December 2006; accepted 14 May 2007)

\begin{abstract}
Transformation behaviors of the technologically important polycrystalline $\mathrm{Ti}_{50.75} \mathrm{Ni}_{47.75} \mathrm{Fe}_{1.50}$ shape memory alloy were investigated using differential scanning calorimeter (DSC) and powder diffraction techniques. DSC revealed that there are two-stage (i.e., cubic $\rightarrow$ trigonal $\rightarrow$ monoclinic) martensitic phase transformations on cooling and a one-step transformation (monoclinic $\rightarrow$ cubic) on heating. In situ structural refinement of cubic $\rightarrow$ trigonal $\rightarrow$ monoclinic on cooling was carried out using the D1A high-resolution neutron powder diffractometer at the Institut Laue-Langevin Neutrons for Science in Grenoble, France. Results showed that the phases involved during the phase transition are consistent with the differential scanning calorimeter cooling curve, and the refined crystal structure parameters obtained from Rietveld refinements with the generalized spherical harmonic description agreed reasonably well with X-ray single-crystal data. Subsequently, a combined neutron and synchrotron structural refinement for each phase was conducted because the trial refinements initially using only the synchrotron data of trigonal phase yielded a false minimum with a somewhat high goodness-of-fit $\chi^{2}$. Results obtained from the combined neutron and synchrotron data of the cubic, trigonal, and monoclinic phases show that the same minimum goodness-of-fit indices were always obtained. (C) 2007 International Centre for Diffraction Data. [DOI: 10.1154/1.2754715]
\end{abstract}

Key words: neutron powder diffraction, generalized spherical harmonic, shape memory alloy, $\mathrm{Ti}-\mathrm{Ni}$, martensitic transformation

\section{INTRODUCTION}

Shape memory and superelasticity effects in $\mathrm{Ti}_{50.75} \mathrm{Ni}_{47.75} \mathrm{Fe}_{1.50}$ ternary alloy heat-treated at $1000{ }^{\circ} \mathrm{C}$ for $1 \mathrm{~h}$ (Hara et al., 1995, 1997) and Ni-rich $\mathrm{Ti}_{49.3} \mathrm{Ni}_{50.7}$ binary alloy aged at $400{ }^{\circ} \mathrm{C}$ for $24 \mathrm{~h}$ (Sitepu et al., 2002a) undergo two-stage martensitic phase transformations. The phase transformations are from the high-temperature cubic structure (or austenite-parent B2 phase) with $P m 3 m$ space group (No. 221) and $Z=1$ via the trigonal structure (or R-phase) with $P \overline{3}$ space group (No. 147), $Z=9$ at room temperature to a monoclinic structure (or martensitic-B19' phase) with $P 112_{1} / m$ space group (No. 11), and $Z=2$ at low-temperature. Figure 1(a) shows the schematic of the two-stage cubic $\rightarrow$ trigonal $\rightarrow$ monoclinic martensitic phase transformations, on cooling, in (1) the heat-treated $\mathrm{Ti}_{50.75} \mathrm{Ni}_{47.75} \mathrm{Fe}_{1.50}$ and the aged Ni-rich $\mathrm{Ti}_{49.3} \mathrm{Ni}_{50.7}$ shape memory alloys (left), and (2) $\mathrm{Ti}_{50} \mathrm{Ni}_{30} \mathrm{Fe}_{20}$ (Miyamoto et al., 2005) alloy (right). Also, the figure shows the one-stage phase transformation (middle) in the annealed $\mathrm{Ti}_{49.86} \mathrm{Ni}_{50.14}$ and $\mathrm{Ti}_{49.3} \mathrm{Ni}_{50.7}$ (Sitepu et al., 2002b; Sitepu and Brokmeier, 2004). The martensitic phase transformation is first order, displacive, athermal, and thermoelastic and can be induced by temperature. Therefore, the cubic phase and trigonal and monoclinic phases have the same chemical compositions.

These technologically important polycrystalline $\mathrm{Ti}_{50.75} \mathrm{Ni}_{47.75} \mathrm{Fe}_{1.50}$ and $\mathrm{Ti}_{49.3} \mathrm{Ni}_{50.7}$ alloys are subject to manufacturing processes that impact a crystallographic preferred orientation of the individual crystal grains within the mate-

${ }^{a)}$ Electronic mail: sitepu@vt.edu rial. The orientation of the grains, or polycrystalline texture, can have a profound effect on the physical properties of a manufactured part, affecting both its strength and possible failure modes, and cause serious systematic errors in phasecomposition analysis and also in crystal structure refinement (Dollase, 1986; Von Dreele, 1997; Wenk et al., 2001; Sitepu et al., 2004a; Sitepu and Brokmeier, 2005). Therefore, correction of powder diffraction intensities because of the effects of preferred orientation is a vital part to determine the crystal structure of the two-stage martensitic phase transformations.

Hara et al. $(1995,1997)$ experimented with electron diffraction and X-ray powder diffraction and showed that (1) addition of the $\mathrm{Fe}_{1.50}$ element yields the trigonal phase, (2) there is no additional peak from the Fe element, and (3) the wire-shaped $\mathrm{Ti}_{50.75} \mathrm{Ni}_{47.75} \mathrm{Fe}_{1.50}$ alloy has a fibered texture with $\langle 111\rangle$ of cubic phase. While the fibered texture information in this alloy proved to be useful information as a qualitative measure of texture [see Figure 1(b)], they did not include the preferred orientation correction in their Rietveld refinements. Therefore, their crystallographic $R_{P}, R_{W P}$, and $R\left(F^{2}\right)$ factors and refined crystal structure parameters of trigonal phase in this alloy need further studies because the powder diffraction pattern from a specimen exhibiting the preferred orientation will display intensity values that differ systematically from those of an ideal sample with random orientation (Sitepu et al., 2001; Sitepu, 2002, 2003; Sitepu et al., 2004b). Recently, Sitepu et al. (2005a) conducted a comparative evaluation of the March model (Dollase, 1986) and generalized spherical harmonic (GSH) description (Bunge, 1982) for preferred orientation using X-ray diffraction data 


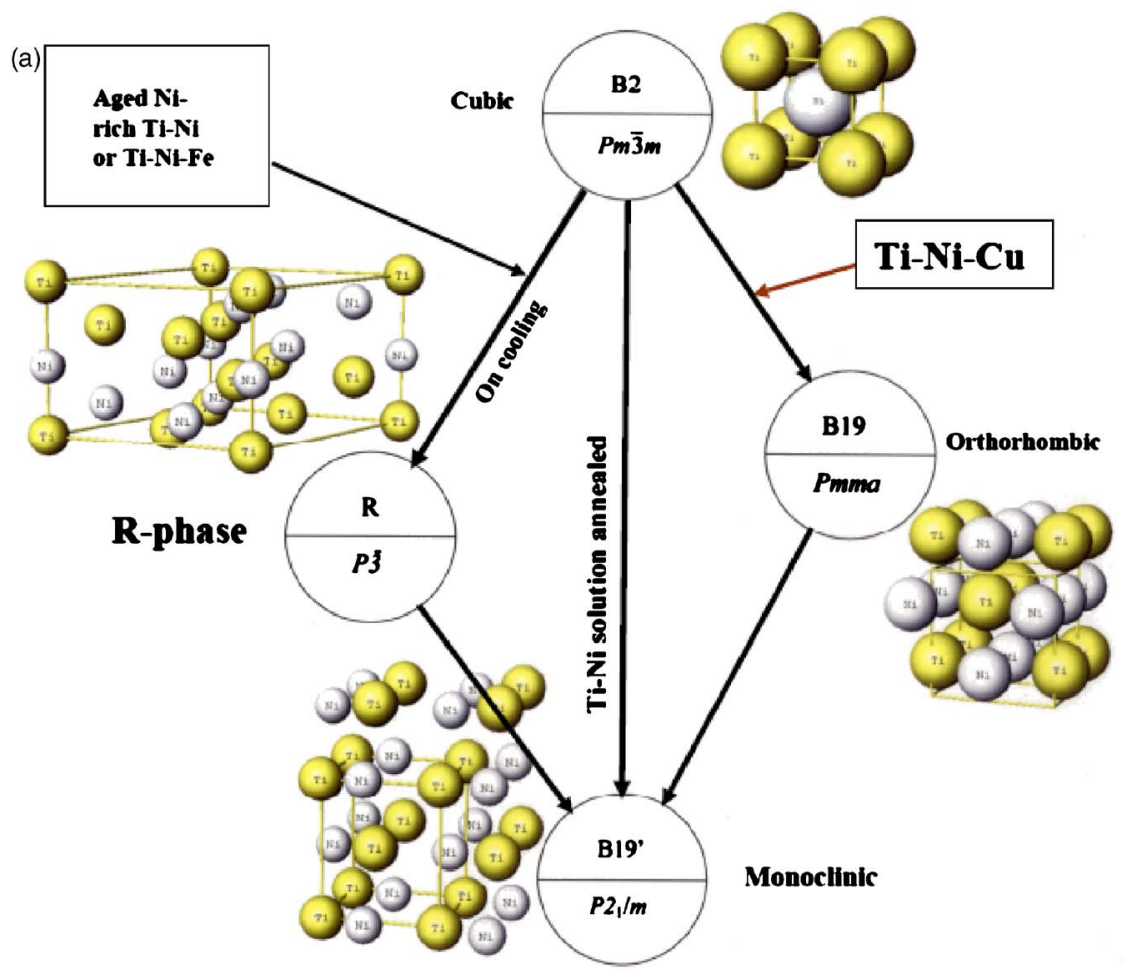

(b) iTi cubic

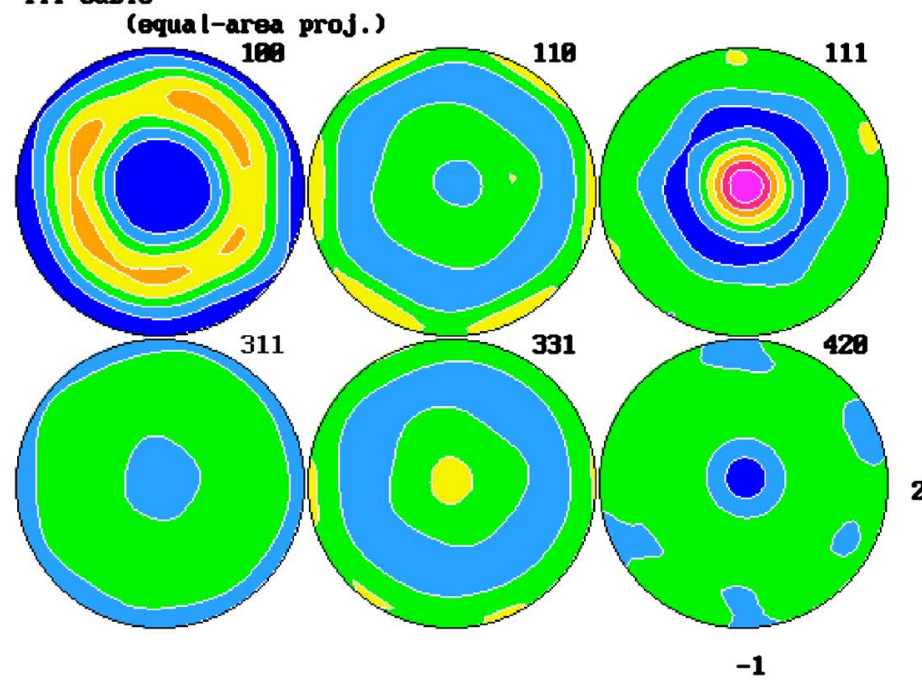

$\max .=2.03$

3.21

2.75

2.29

1.89

1.38

.92

.46

2

lin. scale

3-JUN-**
Figure 1. (a) Three martensitic phase transformation paths in $\mathrm{Ni}-\mathrm{Ti}$ shape memory alloys. (b) Pole-figures of the first six reflections of the cubic phase in $\mathrm{Ti}_{50.75} \cdot \mathrm{Ni}_{47.75} \cdot \mathrm{Fe}_{1.50}$ alloy are given in equal area projection and linear scale. The pole-density scale is shown on the right-hand side and given in multiples of a random distribution. The GSH description was used to extract the texture information from a simultaneous refinement with 99 neutron powder diffraction patterns (personal communication with R. B. Von Dreele) held in a variety of orientations in the HIPPO neutron time-offlight diffractometer at LANSCE. for molybdite and calcite powders uniaxially pressed at five different pressures with the GSAS (Larson and Von Dreele, 2000) Rietveld program. The Rietveld method is well suited for multiphase diffraction data of low-crystal-symmetry materials with many overlapping peaks. The descriptions of the Rietveld refinement programs (i.e., BGMN, DBWS, FullProf, GSAS, LHPM, MAUD, NXD) and links to them can be obtained via the Collaborative Computational Project, Number 14 (CCP14), http://www.ccp14.ac.uk. Sitepu et al. (2005a) showed that the GSH description, which is generated using selection rules depending on the crystal symmetry of the phase under investigation, generally provided superior figures-of-merit $\left[R_{P}, R_{W P}\right.$, and $\left.R\left(F^{2}\right)\right]$ and goodness-of-fit $\left(\chi^{2}\right)$ compared with the March model results.

In the present study, the author uses a differential scanning calorimeter (DSC) to measure phase transformation temperature of the $\mathrm{Ti}_{50.75} \mathrm{Ni}_{47.75} \mathrm{Fe}_{1.50}$ alloy, showing a two- stage cubic $\rightarrow$ trigonal $\rightarrow$ monoclinic martensitic phase transformation on cooling and one-step monoclinic $\rightarrow$ cubic phase transformation on heating [see Figure 2(a)]. In addition, the author uses the high flux neutron source of the Institut LaueLangevin (ILL) Neutrons for Science in Grenoble, France to measure in situ high resolution neutron powder diffraction patterns of the two-stage martensitic phase transformations from cubic via trigonal to monoclinic structure in this alloy. The very different neutron scattering properties of $\mathrm{Ti}$ (i.e., $-3.44 \times 10^{-15} \mathrm{~m}$ ) and $\mathrm{Ni}$ (i.e., $10.30 \times 10^{-15} \mathrm{~m}$ ) allow site occupancies of these two atoms to be established with far greater reliability than can be achieved with X-ray diffraction. The high resolution neutron powder diffraction data for all data sets of the cubic, trigonal, and monoclinic structures were analyzed independently using the GSAS Rietveld analysis with the GSH description, with reference to its use in correcting intensities for preferred orientation bias. Subse- 
quently, combined neutron and synchrotron diffraction data sets for the cubic, trigonal, and monoclinic phases were conducted. This is because the trial refinements initially using only synchrotron diffraction data of the trigonal phase in this alloy [see Figure 2(b)] yielded a false minimum with a somewhat high goodness-of-fit $\chi^{2}$ (Sitepu, 2003).

\section{EXPERIMENTAL}

\section{A. Material and differential scanning calorimeter analysis and synchrotron diffraction}

The heat-treated at $1000{ }^{\circ} \mathrm{C}$ for $1 \mathrm{~h} \mathrm{Ti}_{50.75} \mathrm{Ni}_{47.75} \mathrm{Fe}_{1.50}$ ternary alloy was produced by the Tonkin Corporation and kindly provided by Professor Takuya Ohba of Shimane University [see Hara et al. (1995, 1997), Otsuka and Ren (2005), and references therein]. It should be noted that, on cooling, the composition of this alloy and the heat treatment condition at $1000{ }^{\circ} \mathrm{C}$ for $1 \mathrm{~h}$ were chosen to obtain the stable trigonal phase at room temperature, and an addition of 1.5 atomic percentage of the Fe element yielded the distinction between the first and second DSC temperature peaks of about $25^{\circ} \mathrm{C}$, which are reasonable for structure refinement of two-stage martensitic phase transformations in this alloy. Figure 2(a) depicts the transformation temperatures of this alloy determined by the DSC. DSC results reveal two-stage martensitic phase transformations on cooling and one-stage phase transformation on heating. The trigonal phase martensitic transformation start temperature and finish temperature are $37{ }^{\circ} \mathrm{C}$ and $26^{\circ} \mathrm{C}$, respectively, and the monoclinic phase transformation start and finish temperatures are $11^{\circ} \mathrm{C}$ and $25^{\circ} \mathrm{C}$, respectively. There was no change in the appearance of the DSC data when the experiment was repeated. It should be noted that when this alloy is investigated at $23{ }^{\circ} \mathrm{C}$ it does really matter if this temperature was reached by cooling from high temperatures (i.e., trigonal) or by heating from low temperatures (i.e., monoclinic)—see Figure 2(a).

The goodness-of-fit $\chi^{2}$ obtained by Rietveld refinement for all synchrotron diffraction data sets of the single trigonal phase in this alloy from $(8 \pm 3){ }^{\circ} \mathrm{C}$ to $(38 \pm 3){ }^{\circ} \mathrm{C}$ [see Figure 2(b) ] were described by Sitepu (2003), which yields a false minimum with a somewhat high value (i.e., $8 \times$ exceeding the ideal random powder diffraction value). In the present study, the additional synchrotron diffraction data for the cubic structure at $(60 \pm 3){ }^{\circ} \mathrm{C}$ were measured for $1 \mathrm{~h}$, and data for the monoclinic structure at $(-5 \pm 3){ }^{\circ} \mathrm{C}$ were collected for $6 \mathrm{~h}$ [see Figure 2(b)]. Like the trigonal synchrotron diffraction data at $(22 \pm 3){ }^{\circ} \mathrm{C}$ (Sitepu, 2003), the additional cubic and monoclinic data measured in this study were then processed and, combined for each scan to yield a single diffraction data set. Note that the synchrotron diffraction data are (1) pure cubic phase at $(60 \pm 3){ }^{\circ} \mathrm{C}$, (2) pure trigonal phase at $(22 \pm 3){ }^{\circ} \mathrm{C}$, (3) a mixture of monoclinic and trigonal phases at $(-5 \pm 3)^{\circ} \mathrm{C}$, and (4) not measured below $(-5 \pm 3){ }^{\circ} \mathrm{C}$ because of a limitation of synchrotron beam time.

\section{B. High resolution neutron powder diffraction measurements}

Neutron diffraction data of cubic, trigonal, and monoclinic phases in the $\mathrm{Ti}_{50.75} \mathrm{Ni}_{47.75} \mathrm{Fe}_{1.50}$ shape memory alloy were measured at the ILL high flux neutron source in Grenoble, France, using the D1A (the D1A instrument is described in the ILL Neutron for Science website, http://www.ill.fr/YellowBookCDrom/data/4_1_1.pdf) highresolution fixed-wavelength neutron powder diffractometer. It should be noted that the cylindrical shape of this alloy, $3 \mathrm{~mm}$ in diameter and $9 \mathrm{~mm}$ in height, corresponds to the dimensions of the primary beam, which was chosen using an appropriate collimation. During neutron diffraction data collection, the D1A instrument was equipped with a cryofurnace to heat and cool the alloy (with a temperature constant zone exceeding the length of the rod alloy). The angular $2 \theta$ working range was from $3 \mathrm{deg}$ to $159 \mathrm{deg}$ (25 detectors of type ${ }^{3} \mathrm{He}$ with $6 \mathrm{deg}$ angular range each). Experiments were performed using a neutron wavelength of 1.9114(1) $\AA$ and an angular step size of $0.05 \mathrm{deg}$. After mounting the alloy in the ILL cryofurnace, the alloy was carefully heated to the cubic structure at a temperature of $(113 \pm 3){ }^{\circ} \mathrm{C}$. Prior to the neutron diffraction experiments, the alloy was held at $113{ }^{\circ} \mathrm{C}$ for 6 min so that a thermal-equilibrium condition could be reached. The alloy temperature was then slowly cooled down to $(60 \pm 3){ }^{\circ} \mathrm{C}$ (i.e., the pure cubic structure), and the neutron diffraction data were measured for $2 \mathrm{~h}$. The sample was not spun during the data collection because it was fixed at the cryofurnace. After that, the sample temperature was slowly cooled down to $(22 \pm 3){ }^{\circ} \mathrm{C}$, which is the pure trigonal structure, and the neutron diffraction data were measured for $7 \mathrm{~h}$. Finally, the alloy temperature was slowly cooled down to $(-253 \pm 3){ }^{\circ} \mathrm{C}$, which is the pure monoclinic phase, and the neutron diffraction data were measured for $11 \mathrm{~h}$. The data from the 25 detectors were then processed and combined to yield a single diffraction pattern using interpolations between adjacent observations to correct for zero-point offsets and detector sensitivities. Figure 2(c) shows neutron powder diffraction data are consistent with the DSC results on cooling.

\section{Structural refinement using Rietveld method}

The structural refinements of neutron diffraction data for cubic, trigonal, and monoclinic were conducted using the GSAS Rietveld analysis with the GSH description (Bunge, 1982; Popa, 1992; Von Dreele, 1997). The cubic, trigonal, and monoclinic structural models were described by Wang et al. (1965), Schryvers and Potapov (2002), and Kudoh et al. (1985), respectively. The refinement strategy was first to refine the phase scale factor and the background component of the patterns with a six parameter Chebychev polynomial, followed by adding lattice parameters and zero-point $2 \theta_{0}$ to the refinement, then the Lorentzian and Gaussian terms of the pseudo-Voigt profile function, and the anisotropic strain (Popa, 1998; Stephens, 1999) parameters together with the structural parameters including atomic parameters, isotropic temperature factors, and site occupancies. After the refinement converged, the GSH coefficients were finally added to the refinement. The sample texture symmetry was chosen to be cylindrical, and a maximum six harmonic orders were selected (preliminary calculations with eight orders gave the same results). Subsequently, the combined neutron and synchrotron structural refinement was conducted for each phase. 
(a)
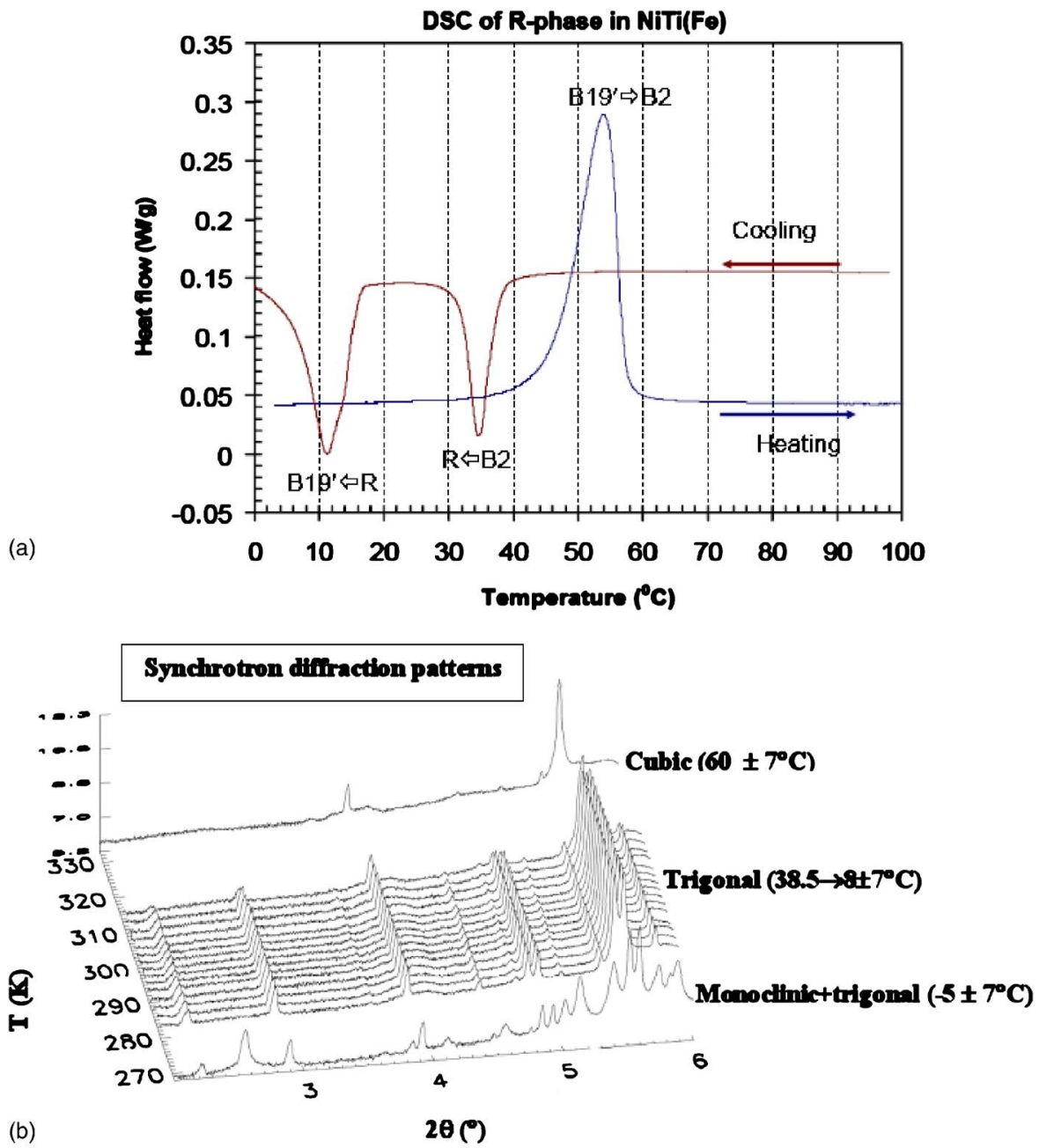

Figure 2. (a) DSC curves for the twostage martensitic phase transformations on cooling and one-stage transformation on heating in $\mathrm{Ti}_{50.75} \mathrm{Ni}_{47.75} \mathrm{Fe}_{1.50}$ alloy. (b) In situ synchrotron structure of cubic $(60 \pm 7)^{\circ} \mathrm{C}, \quad$ trigonal (from 38.5 to $8 \pm 7^{\circ} \mathrm{C}$ ), and the mix of monoclinic and trigonal $(-5 \pm 7)^{\circ} \mathrm{C}$, on cooling. (c) In situ neutron diffraction structure of cubic $(60 \pm 3)^{\circ} \mathrm{C}$, trigonal $(22 \pm 3)^{\circ} \mathrm{C}$, and monoclinic $(-253 \pm 3)^{\circ} \mathrm{C}$ during cooling from high temperature.

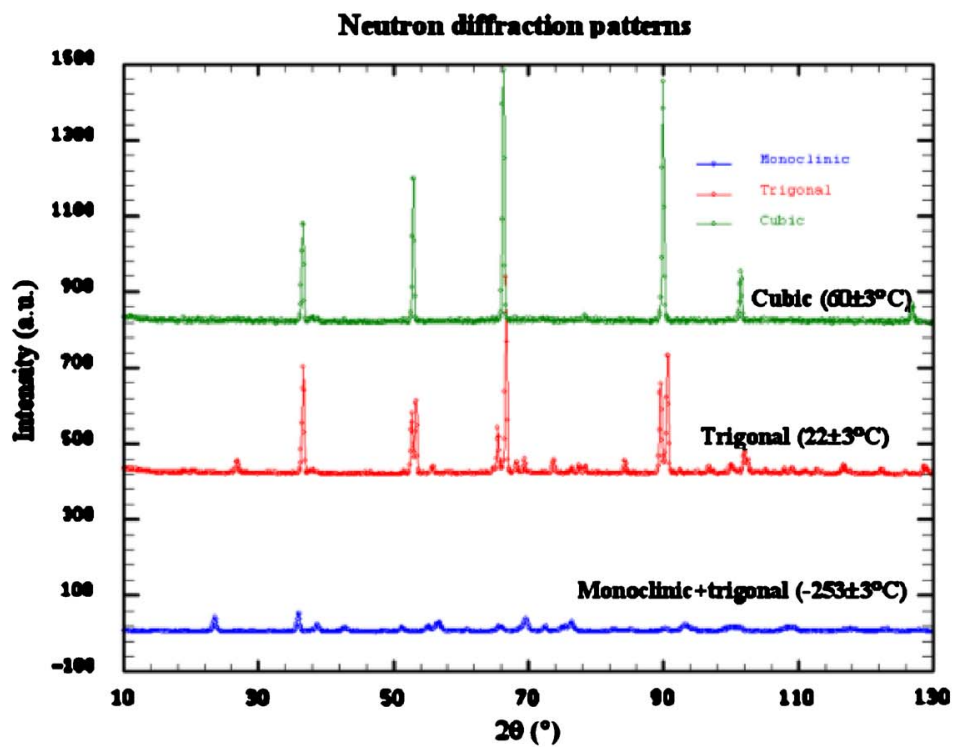

\section{RESULTS AND DISCUSSION}

Figure 2(a) shows that there are two distinct DSC peaks in the $\mathrm{Ti}_{50.75} \mathrm{Ni}_{47.75} \mathrm{Fe}_{1.50}$ shape memory alloy (i.e., two-stage cubic $\rightarrow$ trigonal $\rightarrow$ monoclinic martensitic phase transformations) on cooling, and a one-step monoclinic $\rightarrow$ cubic phase transformation on heating. In addition, when this alloy is investigated at room temperature, it consists of the trigonal structure if this temperature was reached by cooling from high temperatures or the monoclinic structure by heating from low temperatures [see Figure 2(a)]. The pole-figure results obtained from Rietveld refinement with GSH description for all 99 neutron diffraction (personal communication with R. B. Von Dreele) data sets of the cubic structure at various orientations are given in Figure 1(b). The figure 
TABLE I. Refined crystal structure parameters for cubic phase in the $\mathrm{Ti}_{50.75} \mathrm{Ni}_{47.75} \mathrm{Fe}_{1.50}$ alloy at a temperature of $(60 \pm 3){ }^{\circ} \mathrm{C}$. The space group used was $\operatorname{Pm} 3 m$ (No. 221). GOFI=goodness-of-fit index, $f=$ site occupancy, $\mathrm{SRD}=$ synchrotron diffraction, $\mathrm{ND}=$ neutron diffraction, and $\mathrm{N} / \mathrm{A}=$ not available.

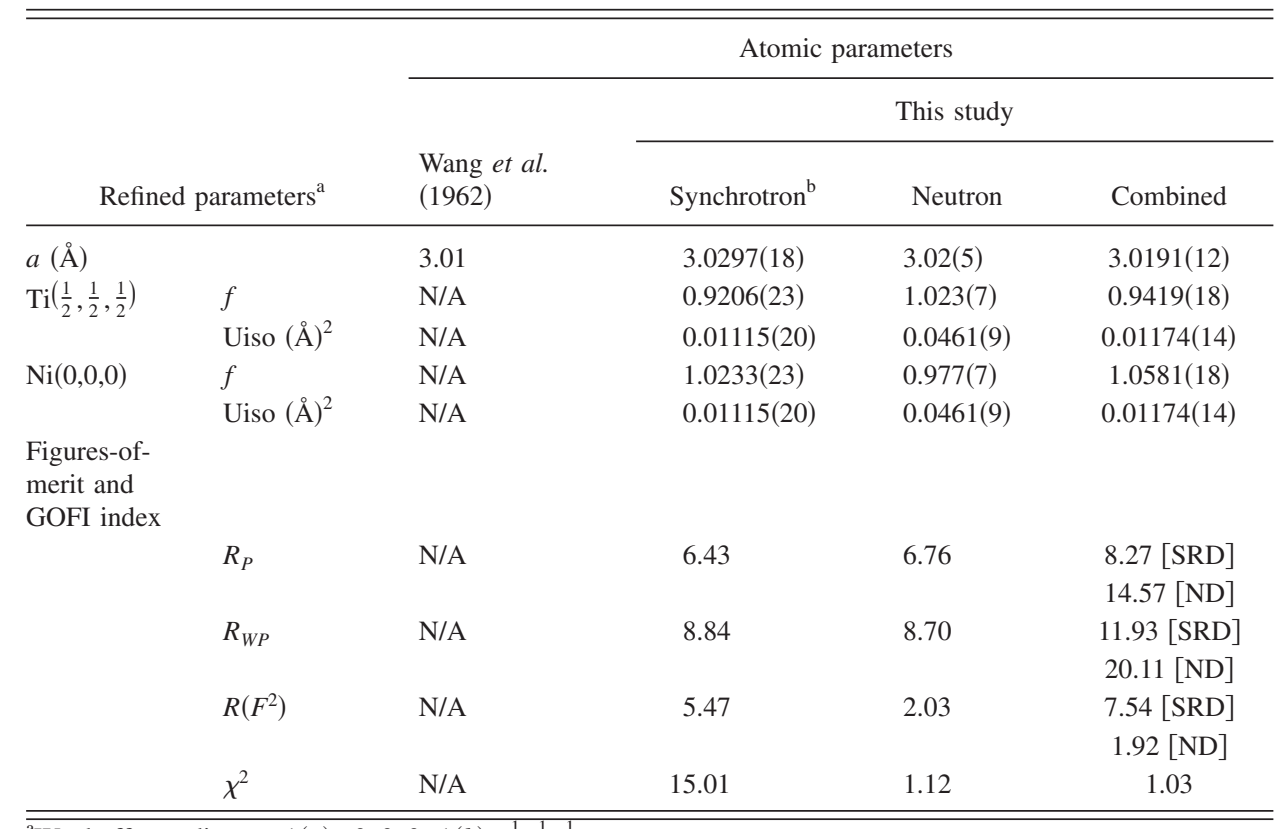

${ }^{a}$ Wyckoff coordinates, $1(a)=0,0,0 ; 1(b)=\frac{1}{2}, \frac{1}{2}, \frac{1}{2}$.

${ }^{\mathrm{b}}$ Synchrotron diffraction data described by Sitepu (2003)—see Figure 2(b).

shows that this alloy has textured with maximum pole figures of two times a random distribution (note that the pole-figure value is unity for ideal random powder diffraction data). Therefore, crystallographic preferred orientation needed to be included in the refinement of all neutron powder diffraction data sets of this alloy because preferred orientation can cause serious systematic errors not only in crystal structure refinement but also in phase composition analysis (see below).

The refined crystal structure parameters derived from Rietveld refinement with the GSH description for cubic, trigonal, and monoclinic structures are given in Tables I, II, and IV, respectively. Table III shows the deviation of the atomic coordinates for the trigonal phase from the positions in the parent cubic structure. Comparison of the Rietveld fits in Figure 3, where neutron and synchrotron data are both plotted with the same $d$-spacing, shows that the peak intensities are quite different in the neutron and synchrotron diffraction data sets, because the neutron has a negative scattering length for Ti. Therefore, when combined neutron and synchrotron refinements were used, there is excellent discrepancy between the two atomic sites.

\section{A. Cubic crystal structure}

A high-temperature single-crystal X-ray diffraction study reported by Wang et al. (1965) reveals a cubic austenite structure (the parent B2 phase) at above the martensitic transformation starting temperature for the Ti-Ni binary alloy with $a=3.01 \AA$, space group Pm3m (No. 221), Ni atoms occupying the $1 a(0,0,0)$ Wyckoff positions, and Ti atoms occupying the $1 b(0.5,0.5,0.5)$ positions (see Table I). However, no isotropic temperature factors are reported.

In this study, the results obtained from Rietveld refinement with the GSH description for neutron and synchrotron powder diffraction data of the cubic phase in $\mathrm{Ti}_{50.75} \mathrm{Ni}_{47.75} \mathrm{Fe}_{1.50}$ alloy at $(60 \pm 3){ }^{\circ} \mathrm{C}$ agree reasonably well with single-crystal X-ray diffraction data reported by Wang et al. (1965). The $\mathrm{Ni}$ and $\mathrm{Ti}$ isotropic temperature factors (Uiso) for neutron diffraction data are approximately four times higher than those of the corresponding synchrotron values. The neutron site occupancy value for $\mathrm{Ti}$ is higher than that of the synchrotron, whereas the corresponding site occupancy value for $\mathrm{Ni}$ is vice versa. While the neutron crystallographic $R_{W P}$ and $R_{P}$ factors are almost the same as those of the synchrotron, both the crystallographic $R\left(F^{2}\right)$ and goodness-of-fit $\chi^{2}$ values for the neutron are far superior to that of the synchrotron. This indicates that the refinement using only the single synchrotron data found a false minimum with somewhat worse $\chi^{2}$ than those of neutron diffraction data. When combined neutron and synchrotron powder diffraction data sets were used in Rietveld refinements, practically the same minimum $\chi^{2}$ was always obtained. It should be noted that, while the combined refinement provides the neutron $R\left(F^{2}\right)$ value superior to that of the synchrotron data, the $R_{W P}$ and $R_{P}$ values for the neutron are vice versa. Figure 3 shows the results of the Rietveld fits for the cubic phase at $(60 \pm 3)^{\circ} \mathrm{C}$. Because the scattering factor for $\mathrm{Ti}$ is -3.44 $\times 10^{-15} \mathrm{~m}$, the peak intensities are quite different in both the synchrotron and neutron diffraction data sets. Therefore, a combined structural refinement of both synchrotron and neutron diffraction data sets is an excellent way to determine the crystal structures of the $\mathrm{Ti}_{50.75} \mathrm{Ni}_{47.75} \mathrm{Fe}_{1.50}$ alloy.

\section{B. Trigonal crystal structure}

Schryver and Patapov (2002), Sitepu (2003), and Sitepu et al. (2005b) reported that no significant improvement in Rietveld fit was found when the inversion center was re- 
TABLE II. Refined crystal structure parameters for the trigonal phase in the $\mathrm{Ti}_{50.75} \mathrm{Ni}_{47.75} \mathrm{Fe}_{1.50}$ alloy at a temperature of $(22 \pm 3)^{\circ} \mathrm{C}$. The space group used was $P \overline{3}$ (No. 147). GOFI=goodness-of-fit index, $f=$ site occupancy, $\mathrm{SRD}=$ synchrotron diffraction, $\mathrm{ND}=$ neutron diffraction, and $\mathrm{N} / \mathrm{A}=$ not available.

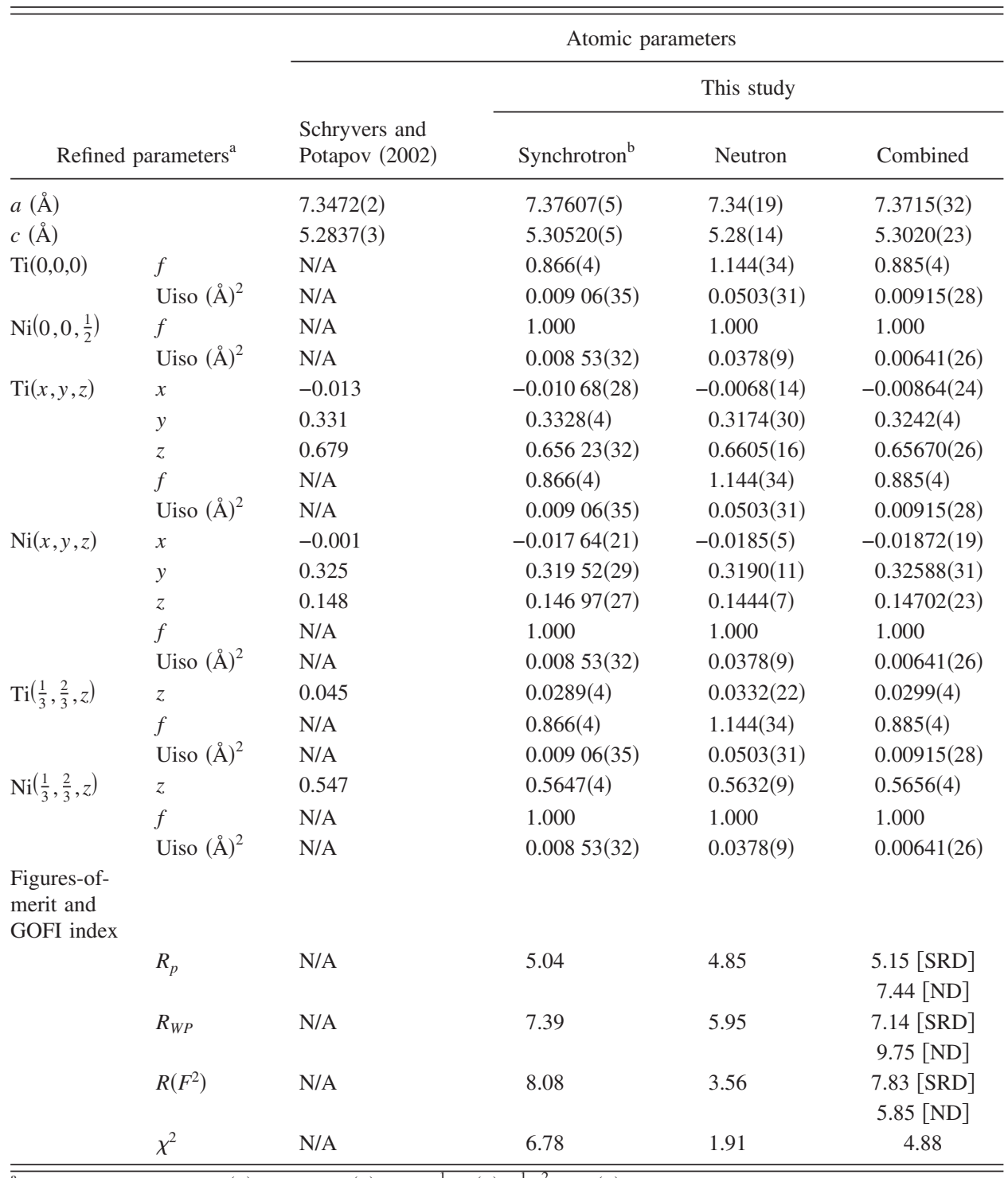

${ }^{\mathrm{a}}$ Wyckoff coordinates, $1(a)=0,0,0 ; 1(b)=0,0, \frac{1}{2} ; 2(d)=\frac{1}{3}, \frac{2}{3}, z ; 6(g)=x, y, z$.

${ }^{\mathrm{b}}$ Synchrotron diffraction data described by Sitepu (2003) — see Figure 2(b).

moved from the $P \overline{3}$ model. This suggests that the space group for the trigonal structure in the $\mathrm{Ti}_{50.75} \mathrm{Ni}_{47.75} \mathrm{Fe}_{1.50}$ alloy after cooling to room temperature was indeed $P \overline{3}$, not lower symmetry $P 3$ or $P 31 \mathrm{~m}$. In addition, the refined atomic parameters for all synchrotron diffraction data sets of the trigonal phase were converging only when the $P \overline{3}$ space group was used in the Rietveld refinement (Sitepu, 2003; Sitepu et al., 2005b).

In the present study, the results obtained from Rietveld refinement with GSH description for (1) single neutron, (2) single synchrotron, and (3) combined neutron and synchrotron diffraction data of trigonal structure at $(22 \pm 3){ }^{\circ} \mathrm{C}$, on cooling, are given in Table II. The values in parentheses are estimated standard deviations. The refined atomic parameters for synchrotron data agree reasonably well with the transmission electron microscope results reported by Schryver and Patapov (2002). The neutron Ti atomic site occupancy $(f)$
TABLE III. Deviations of the atomic co-ordinates for the combined neutron and synchrotron diffraction data sets of trigonal (or $R$-phase) at a temperature of $(22 \pm 3){ }^{\circ} \mathrm{C}$ from the positions in the parent cubic (or B2) structure. The space group used was $P \overline{3}$ (No. 147).

\begin{tabular}{|c|c|c|c|}
\hline \multirow[b]{2}{*}{ Parameters $^{\mathrm{a}}$} & \multicolumn{3}{|c|}{ Deviation from the positions of the parent cubic structure } \\
\hline & $\Delta x$ & $\Delta y$ & $\Delta z$ \\
\hline $\operatorname{Ti}(0,0,0)$ & - & - & - \\
\hline $\mathrm{Ni}\left(0,0, \frac{1}{2}\right)$ & - & - & - \\
\hline $\operatorname{Ti}(x, y, z)$ & -0.00864 & -0.0091 & -0.00966 \\
\hline $\mathrm{Ni}(x, y, z)$ & -0.01872 & -0.00966 & 0.02202 \\
\hline $\operatorname{Ti}\left(\frac{1}{3}, \frac{2}{3}, z\right)$ & - & - & 0.0299 \\
\hline $\mathrm{Ni}\left(\frac{1}{3}, \frac{2}{3}, z\right)$ & - & - & 0.06383 \\
\hline
\end{tabular}

$\overline{\overline{\mathrm{a}} \text { Wyckoff coordinates, } 1(a)=0,0,0 ; 1(b)=0,0, \frac{1}{2} ; 2(d)=\frac{1}{3}, \frac{2}{3}, z ; 6(g)=x, y, z}$. 
TABLE IV. Refined crystal structure parameters for mix of monoclinic and trigonal phases at $(-5 \pm 7){ }^{\circ} \mathrm{C}$ for synchrotron and at $(-253 \pm 3){ }^{\circ} \mathrm{C}$ for neutron. The space groups used were $P 112_{1} / m$ (No. 11) for monoclinic and $P \overline{3}$ (No. 147) for trigonal. GOFI=goodness-of-fit index, $f=$ site occupancy, SRD=synchrotron diffraction, $\mathrm{ND}=$ neutron diffraction, and $\mathrm{Wt}(\%)=$ weight percentage of monoclinic and trigonal phase for synchrotron data only.

\begin{tabular}{|c|c|c|c|c|c|}
\hline \multirow{2}{*}{\multicolumn{2}{|c|}{ Refined parameters ${ }^{\mathrm{a}, \mathrm{b}}$}} & \multicolumn{4}{|c|}{ Atomic parameters } \\
\hline & & \multirow{2}{*}{$\begin{array}{l}\text { Kudoh et al. } \\
\quad(1985)\end{array}$} & \multicolumn{3}{|c|}{ This study } \\
\hline \multicolumn{2}{|c|}{ Monoclinic phase } & & Synchrotron $^{\mathrm{c}}$ & Neutron & Combined \\
\hline \multirow{3}{*}{\multicolumn{2}{|c|}{$\begin{array}{l}a(\AA) \\
b(\AA) \\
c(\AA)\end{array}$}} & $2.898(1)$ & $2.8886(1)$ & $2.8731(7)$ & $2.92617(14)$ \\
\hline & & $4.108(2)$ & $4.1224(3)$ & $4.0905(7)$ & $4.17272(10)$ \\
\hline & & $4.646(3)$ & $4.6453(4)$ & $4.6465(10)$ & $4.69631(25)$ \\
\hline \multicolumn{2}{|l|}{$\beta\left({ }^{\circ}\right)$} & $97.78(4)$ & $97.505(4)$ & $98.165(20)$ & $97.4036(35)$ \\
\hline \multirow[t]{4}{*}{$\operatorname{Ti}\left(x, y, \frac{1}{4}\right)$} & $x$ & $0.5824(5)$ & $0.5995(2)$ & $0.582(6)$ & $0.5822(9)$ \\
\hline & $y$ & $0.2836(3)$ & $0.309(1)$ & $0.2891(35)$ & $0.2884(8)$ \\
\hline & $f$ & N/A & $0.984(4)$ & $0.920(18)$ & $0.921(4)$ \\
\hline & Uiso $(\AA)^{2}$ & 0.0107 & $0.0186(5)$ & $0.0019(21)$ & $0.0100(4)$ \\
\hline \multirow{4}{*}{$\mathrm{Ni}\left(\bar{x}, \bar{y}, \frac{3}{4}\right)$} & $x$ & $0.0372(4)$ & $0.0139(10)$ & $0.0354(20)$ & $0.0260(8)$ \\
\hline & $y$ & $0.1752(2)$ & $0.1504(9)$ & $0.1739(11)$ & $0.1757(6)$ \\
\hline & $f$ & N/A & $1.078(10)$ & $1.080(18)$ & $1.079(4)$ \\
\hline & Uiso $(\AA)^{2}$ & 0.0126 & $0.0127(4)$ & $0.0019(21)$ & $0.0100(4)$ \\
\hline \multicolumn{2}{|c|}{ Trigonal phase } & \multicolumn{4}{|c|}{$\begin{array}{l}\text { Schryvers and Potapov } \\
(2002)\end{array}$} \\
\hline \multirow{3}{*}{\multicolumn{2}{|c|}{$\begin{array}{l}a(\AA) \\
c(\AA)\end{array}$}} & $7.3472(2)$ & $7.3681(8)$ & & $7.37834(2)$ \\
\hline & & $5.2837(3)$ & $5.3135(6)$ & & $5.32089(4)$ \\
\hline & $f$ & N/A & $0.871(4)$ & & $0.885(4)$ \\
\hline $\operatorname{Ti}(0,0,0)$ & Uiso $(\AA)^{2}$ & N/A & $0.0115(5)$ & & $0.00915(28)$ \\
\hline \multirow{2}{*}{$\mathrm{Ni}\left(0,0, \frac{1}{2}\right)$} & $f$ & N/A & 1.000 & & 1.000 \\
\hline & Uiso $(\AA)^{2}$ & N/A & $0.0068(4)$ & & $0.00641(26)$ \\
\hline \multirow[t]{5}{*}{$\operatorname{Ti}(x, y, z)$} & $x$ & -0.013 & $-0.0125(5)$ & & $-0.008664(24)$ \\
\hline & $y$ & 0.331 & $0.3247(7)$ & & $0.3242(4)$ \\
\hline & $z$ & 0.679 & $0.6533(6)$ & & $0.65670(26)$ \\
\hline & $f$ & N/A & $0.871(4)$ & & $0.885(4)$ \\
\hline & Uiso $(\AA)^{2}$ & N/A & $0.0115(5)$ & & $0.00915(28)$ \\
\hline \multirow{5}{*}{$\mathrm{Ni}(x, y, z)$} & $x$ & -0.001 & $-0.01712(35)$ & & $-0.01872(19)$ \\
\hline & $y$ & 0.325 & $0.3283(5)$ & & $0.32588(31)$ \\
\hline & $z$ & 0.148 & $0.1497(5)$ & & $0.14702(23)$ \\
\hline & $f$ & N/A & 1.000 & & 1.000 \\
\hline & Uiso $(\AA)^{2}$ & N/A & $0.0068(4)$ & & $0.00641(26)$ \\
\hline \multirow{3}{*}{$\operatorname{Ti}\left(\frac{1}{3}, \frac{2}{3}, z\right)$} & $z$ & 0.045 & $0.0318(7)$ & & $0.0299(4)$ \\
\hline & $f$ & N/A & $0.871(4)$ & & $0.885(4)$ \\
\hline & Uiso $(\AA)^{2}$ & N/A & $0.0115(5)$ & & $0.00915(28)$ \\
\hline \multirow{3}{*}{$\mathrm{Ni}\left(\frac{1}{3}, \frac{2}{3}, z\right)$} & $z$ & 0.547 & $0.5703(7)$ & & $0.5656(4)$ \\
\hline & $f$ & N/A & 1.000 & & 1.000 \\
\hline & Uiso $(\AA)^{2}$ & N/A & $0.0068(4)$ & & $0.00641(26)$ \\
\hline \multicolumn{6}{|l|}{$\begin{array}{l}\text { Figures-of- } \\
\text { merit and } \\
\text { GOFI index }\end{array}$} \\
\hline & $R_{P}$ & N/A & 5.58 & 9.46 & $\begin{array}{l}4.73[\mathrm{SRD}] \\
15.98[\mathrm{ND}]\end{array}$ \\
\hline & $R_{W P}$ & N/A & 7.87 & 11.70 & $\begin{array}{l}6.58[\mathrm{SRD}] \\
20.70[\mathrm{ND}]\end{array}$ \\
\hline & $R\left(F^{2}\right)$ & N/A & 8.86 & 4.20 & $\begin{array}{l}5.80[\mathrm{SRD}] \\
12.80[\mathrm{ND}]\end{array}$ \\
\hline & $\chi^{2}$ & N/A & 7.14 & 1.19 & 4.38 \\
\hline \multicolumn{5}{|l|}{$\mathrm{Wt}(\%)$ for } & 37.47 [SRD] \\
\hline \multicolumn{2}{|l|}{ - monoclinic } & & & & $100.00[\mathrm{ND}]$ \\
\hline \multirow[t]{2}{*}{ - trigonal } & & & 61.45 [SRD] & $0.00[\mathrm{ND}]$ & $62.52[\mathrm{SRD}]$ \\
\hline & & & & & $0.00[\mathrm{ND}]$ \\
\hline
\end{tabular}

${ }^{\mathrm{a} W y c k o f f}$ coordinates, $2(e)=x, y, \frac{1}{4} ; 2(e)=\bar{x}, \bar{y}, \frac{3}{4}$ for monoclinic.

${ }^{\mathrm{b}}$ Wyckoff coordinates, $1(a)=0,0,0 ; 1(b)=0,0, \frac{1}{2} ; 2(d)=\frac{1}{3}, \frac{2}{3}, z ; 6(g)=x, y, z$ for trigonal.

${ }^{\mathrm{c}}$ Synchrotron diffraction data described by Sitepu (2003)—see Figure 2(b). 
value is higher than that of the synchrotron, while the Ti and $\mathrm{Ni}$ isotropic temperatures (Uiso) for the neutron are less than those for the synchrotron. Results obtained from the combined refinement show (1) the Ti site occupancy value and the $\mathrm{Ni}$ isotropic temperature factor are between the synchrotron and neutron values and (2) the isotropic temperature factor for Ti has a discernible decimal change from synchrotron refinement only. In addition, the results show that the neutron diffraction data provide superior the crystallographic $R_{W P}$ and $R_{P}$ factors compared to that of the synchrotron data for the trigonal phase. However, when the combined neutron and synchrotron refinement was conducted, it provided a goodness-of-fit $\chi^{2}$ lower than that of the synchrotron data refinement only. This result confirms the conclusions for the cubic phase indicating that the same minimum goodness-offit was always recovered when combined neutron and synchrotron data sets was used whereas the refinement using only the synchrotron data originally conducted by Sitepu (2003) sometimes found a false minimum with somewhat high goodness-of-fit value.

The results obtained from combined neutron and synchrotron diffraction data of the trigonal phase at $(22 \pm 3){ }^{\circ} \mathrm{C}$ confirm the previous study conducted by Sitepu (2003) that $P \overline{3}$ is the right space group. All eight atomic parameters converged and the $R_{W P}$ and $R\left(F^{2}\right)$ values are 7.14 and 7.83 for the synchrotron and 9.75 and 5.85 for the neutron, respectively. In comparison, the crystallographic $R_{W P}$ and $R\left(F^{2}\right)$ factors reported by Hara et al. $(1995,1997)$ with 17 positional parameters for the trigonal phase of $\mathrm{Ti}_{50.75} \mathrm{Ni}_{47.75} \mathrm{Fe}_{1.50}$ were 8.47 and 23.83, respectively. Their $R\left(F^{2}\right)$ value of 23.83 obtained from X-ray powder diffraction data is twice higher than that obtained from the combined synchrotron and neutron fits. This shows that preferred crystallographic orientation should be taken with great care in order to obtain accurate structure refinement results. Therefore, it can be concluded that the combined synchrotron and neutron structural study for the trigonal phase in the $P \overline{3}$ model provides accurate crystal structure parameters when applying corrections to the experimental intensities using the GSH description.

Table III shows the deviation of the trigonal atomic coordinates from the position in the parent cubic phase (or B2) structure. While the deviations of the $z$ coordinate from the $\operatorname{Ti}(x, y, z)$ and $\operatorname{Ti}\left(\frac{1}{3}, \frac{2}{3}, z\right)$ atoms in the parent cubic structure are $-0.00966 c$ and $0.0299 c$, respectively, the $\operatorname{Ti}(x, y, z)$ shift value is very small. The corresponding deviation of $z$ coordinates for the $\mathrm{Ni}(x, y, z)$ and $\mathrm{Ni}\left(\frac{1}{3}, \frac{2}{3}, z\right)$ are $0.02202 c$ and $0.06383 c$, respectively, which are twice higher than that of the $\operatorname{Ti}(x, y, z)$ and $\operatorname{Ti}\left(\frac{1}{3}, \frac{2}{3}, z\right)$ atoms. These $z$-coordinate deviations for $\mathrm{Ti}(x, y, z), \mathrm{Ti}\left(\frac{1}{3}, \frac{2}{3}, z\right), \mathrm{Ni}(x, y, z)$, and $\mathrm{Ni}\left(\frac{1}{3}, \frac{2}{3}, z\right)$ are smaller than those reported by Hara et al. (1995) and Schryvers and Potapov (2002).

\section{Monoclinic crystal structure}

Kudoh et al. (1985) reported that single-crystal X-ray crystal-structure analysis of the monoclinic (or martensiticB19' phase) in $\mathrm{Ni}_{49.2} \mathrm{Ti}_{50.8}$ alloy with unit-cell parameters of $a=2.898(1) \AA, \quad b=4.108(2) \AA, \quad c=4.646(3) \AA, \quad$ and $\gamma$ $=97.78(1)^{\circ}$. The space group was $P 112_{1} / m$ (No. 11), which agreed well with the result published by Michal and Sinclair (1981). Ti atoms occupied $2 e(0.5824,0.2836,0.25)$ Wyckoff positions and $\mathrm{Ni}$ atom were at $2 e(0.0372,0.1752,0.75)$.

Table IV shows the monoclinic crystal-structure parameters determined from Rietveld refinement with GSH description for neutron diffraction data at $(-253 \pm 3){ }^{\circ} \mathrm{C}$ and synchrotron diffraction data at $(-5 \pm 3){ }^{\circ} \mathrm{C}$. The values in parentheses are estimated standard deviations. The neutron diffraction data reveal a pure monoclinic phase, whereas synchrotron data show a mixture of monoclinic and trigonal phases. This indicated that the parent structure has not fully transformed to monoclinic at $(-5 \pm 3){ }^{\circ} \mathrm{C}$ [see Figures 2(a) and 2(b)]. The cell parameters agree reasonably well with X-ray single-crystal results reported by Kudoh et al. (1985). The refined monoclinic atomic parameters for single neutron, single synchrotron, and combined refinement agree reasonably well with the X-ray single-crystal results reported by Kudoh et al. (1985). The neutron $\operatorname{Ti}\left(x, y, \frac{1}{4}\right)$ and $\mathrm{Ni}\left(\bar{x}, \bar{y}, \frac{3}{4}\right)$ atoms have values for both site occupancies and isotropic temperature factors lower than the synchrotron data. In addition, when the combined refinement was conducted, the $\mathrm{Ti}\left(x, y, \frac{1}{4}\right)$ and $\mathrm{Ni}\left(\bar{x}, \bar{y}, \frac{3}{4}\right)$ site occupancies and isotropic temperature factors are between the single synchrotron refinement results and neutron values. Moreover, the refined trigonal atomic parameters for single synchrotron diffraction data and also for the combined refinement neutron and synchrotron data sets agree reasonably well with the results published by Schryver and Popatov (2002).

While the neutron crystallographic $R\left(F^{2}\right)$ and goodnessof-fit $\chi^{2}$ values for the monoclinic provide superior results compared to those of the single synchrotron data, the crystallographic $R_{P}$ and $R_{W P}$ factors for the neutron are worse than the synchrotron data. When the combined refinement was conducted, it provided a $\chi^{2}$ value lower than that of the single synchrotron data. This result confirms the conclusions for the cubic and trigonal phases in which practically the same $\chi^{2}$ minimum was always obtained when a combined refinement was conducted. On the other hand, the refinement using only the synchrotron data sometimes found a false minimum with somewhat high $\chi^{2}$. Since the neutron diffraction data at $(-273 \pm 3){ }^{\circ} \mathrm{C}$ consists of a single monoclinic phase [see Figures 2(c) and 3(b)], the neutron crystallographic $R_{P}, R_{W P}$, and $R\left(F^{2}\right)$ figures-of-merit are higher than those of the synchrotron because the synchrotron diffraction data consist of a mixture of monoclinic and trigonal phases [see Figures 2(b) and 3(a)].

The weight percentages of monoclinic and trigonal phases are 38.55 and 61.45 for the synchrotron and 100.00 and 0.00 for the neutron, respectively. The corresponding monoclinic and trigonal weight percentages obtained from the combined refinement are 37.47 and 62.52 for the synchrotron and 100.00 and 0.00 for the neutron, respectively. Therefore, it can be concluded that the GSH description can be used successfully to correct the neutron diffraction intensities attributable to the effects of preferred orientation for the purposes of determining crystal-structure information and phase-composition analysis of the two-stage martensitic phase transformations. 


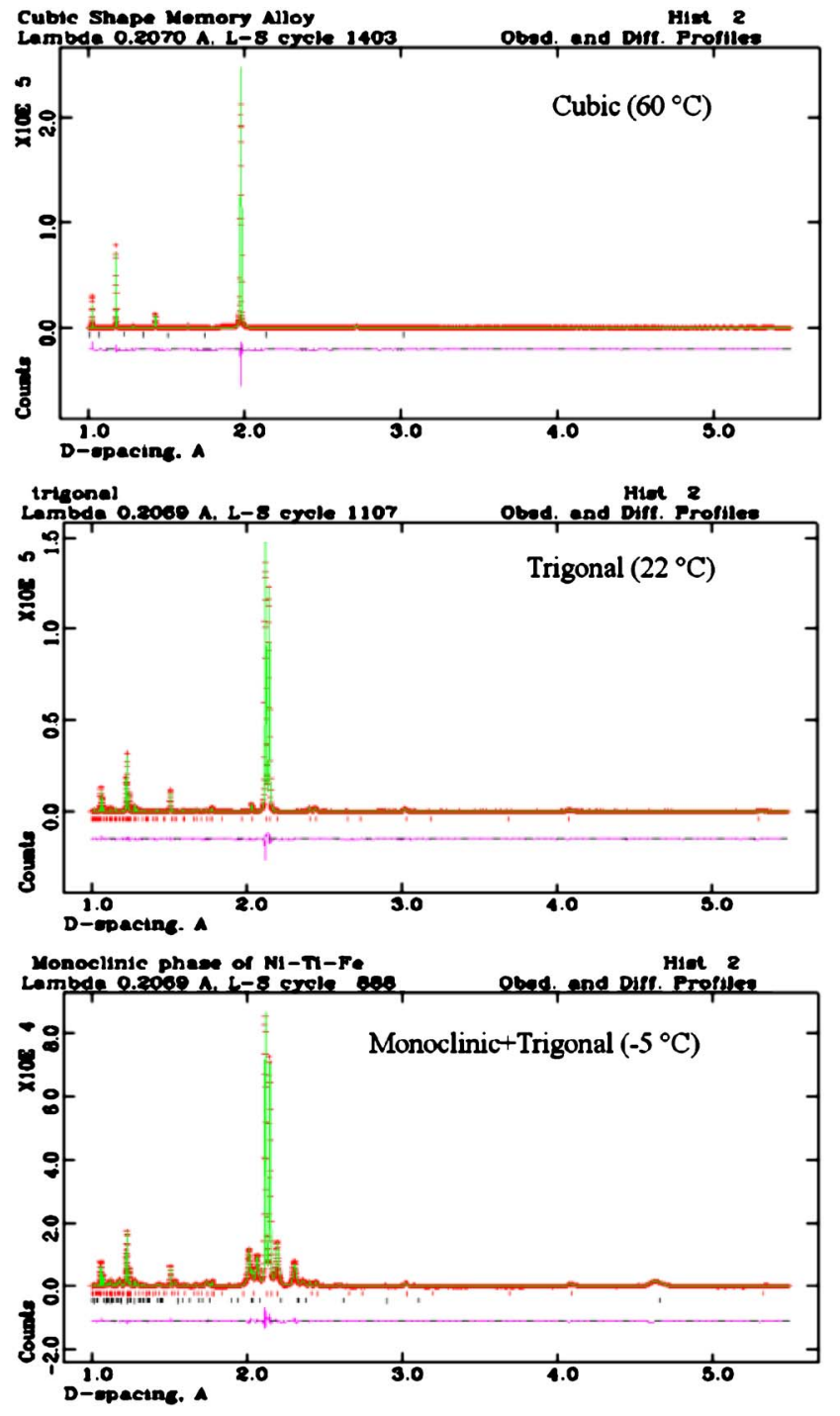

(a) Synchrotron
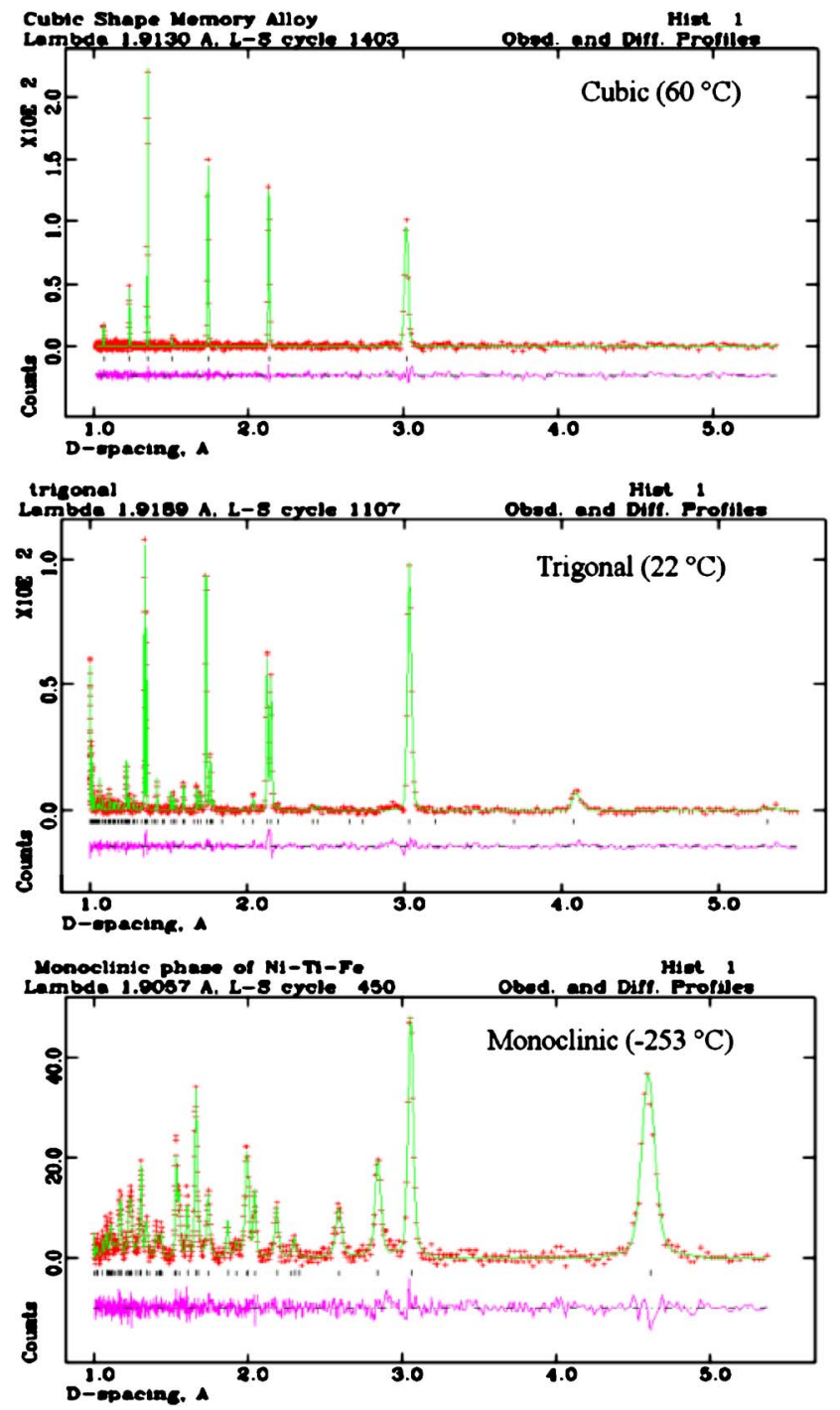

(b) Neutron

Figure 3. Comparison of Rietveld fits of (a) synchrotron and (b) neutron diffraction patterns for cubic, trigonal, and monoclinic phases in $\mathrm{Ti}_{50.75} \mathrm{Ni}_{47.75} \mathrm{Fe}_{1.50}$ alloy are plotted at the same $d$-spacing. The observed data are indicated by plus signs, and the calculated profile is the continuous line in the same field. The lower plot is the difference between the measured and calculated patterns on the same scale as the measured and calculated patterns.

\section{CONCLUSIONS}

The present study investigates the phase transition behaviour of technologically important polycrystalline $\mathrm{Ti}_{50.75} \mathrm{Ni}_{47.75} \mathrm{Fe}_{1.50}$ shape memory alloy using DSC, and in situ crystal structure determination of phases involved on cooling using Rietveld refinement with GSH description for preferred orientation in neutron and combined neutron and synchrotron data. The following conclusions can be drawn:

The DSC results showed that this alloy has two-stage cubic $\rightarrow$ trigonal $\rightarrow$ monoclinic martensitic phase transformations on cooling and a one-stage monoclinic $\rightarrow$ cubic phase transformation on heating.

The preliminary texture results obtained in this study [see Figure 1(b)] show that this alloy has a texture where the maximum pole-figures are two times multiple-of-random distribution. Thus, the preferred orientation correction must be taken with great care in determining the crystal structure of neutron powder diffraction data of two-stage martensitic phase transformations on cooling.

In situ neutron diffraction data sets of cubic, trigonal, and monoclinic structures are consistent with the DSC cooling curve [see Table IV and Figures 2(a)-2(c)].

The refined crystal structure parameters for neutron diffraction data of cubic, trigonal, and monoclinic agreed quite satisfactorily with X-ray single-crystal data (see Tables I, II, and IV). Therefore, the GSH description can be used for correction of preferred orientation in neutron diffraction data analysis for both crystal-structure refinement and phasecomposition analysis.

When combined neutron and synchrotron structural refinements of cubic, trigonal, and monoclinic were conducted (see Tables I, II, and IV), the same minimum goodness-of-fit $\chi^{2}$ was always recovered, whereas trial refinements initially 
conducted by Sitepu (2003) using the single synchrotron data sometimes found a false minimum with a somewhat worse goodness-of-fit.

\section{ACKNOWLEDGMENTS}

Professor Takuya Ohba (Shimane University) is greatly appreciated for his help in providing the $\mathrm{Ti}_{50.75} \mathrm{Ni}_{47.75} \mathrm{Fe}_{1.50}$ alloy. Thanks are owed to C. Ritter of ILL, F. Fauth of ESRF, and S. C. Vogel of LANSCE for invaluable contributions in collecting and interpreting the data. A. W. Hewat of ILL and J. W. Wright of ESRF are gratefully acknowledged for their help in conducting the refinement with the centre symmetry of the trigonal structure and combined neutron and synchrotron structural refinement of trigonal phase. The author would like also to acknowledge COMPRES under NSF Cooperative Agreement No. EAR 01-35554 for financial support and also to ESRF, ILL, and LANSCE for providing the ID31, D1A, and HIPPO beam time.

Bunge, H.-J. (1982). Texture Analysis in Materials Science: Mathematical Methods, translated by P. R. Morris (Butterworth-Heinemann, London).

Dollase, W. A. (1986). "Correction of intensities for preferred orientation in powder diffractometry: application of the March model," J. Appl. Crystallogr. 19, 267-272.

Hara, T., Ohba, T., and Otsuka, K. (1995). "Structural study of the R-phase in Ti-Ni alloy by the Rietveld method," J. Phys. III 5, 641-645.

Hara, T., Ohba, T., Okunishi, E., and Otsuka, K. (1997). "Structural study of R-phase in $\mathrm{Ti}_{50.23} \mathrm{Ni}$ and $\mathrm{Ti}_{50.75} \mathrm{Ni}_{47.75} \mathrm{Fe}_{1.50}$ alloy," Mater. Trans., JIM 38, 11-17.

Kudoh, Y., Tokonami, M., Miyazaki, S., and Otsuka, K. (1985). "Crystal structure of the mertensite in $\mathrm{Ti}_{50.80} \mathrm{Ni}_{49.20}$ alloy analyzed by the single crystal X-ray diffraction method," Acta Metall. 33, 2049-2056.

Larson, A. C. and Von Dreele, R. B. (2000). General Structure Analysis System (GSAS), Report LAUR 86-748, Los Alamos National Laboratory, Los Alamos, NM.

Michal, G. M. and Sinclair, R. (1981). "The structure of TiNi martensite," Acta Crystallogr., Sect. B: Struct. Crystallogr. Cryst. Chem. 37, 18031807.

Miyamoto, H., Taniwaki, T., Ohba, T., Otsuka, K., Nishigori, S., and Kato, K. (2005). "Two stage B2-B19-B19' martensitic transformation in a $\mathrm{Ti}_{50} \mathrm{Ni}_{30} \mathrm{Cu}_{20}$ alloy observed by synchrotron radiation," Scr. Mater. 53, 171-175.

Otsuka, K. and Ren, X. (2005). "Physical metallurgy of Ti-Ni-based shape memory alloys," Prog. Mater. Sci. 50, 511-678.

Popa, N. C. (1992). "Texture in Rietveld refinement," J. Appl. Crystallogr. 25, 611-616.

Popa, N. C. (1998). "The $(h k l)$ Dependence of Diffraction-Line Broadening
Caused by Strain and Size for all Laue Groups in Rietveld Refinement," J. Appl. Crystallogr. 31, 176-180.

Schryvers, D. and Potapov, P. L. (2002). "R-Phase Structure Refinement Using Electron Diffraction Data," Mater. Trans., JIM 43, 774-779.

Sitepu, H. (2002). "Assessment of preferred orientation with neutron powder diffraction data," J. Appl. Crystallogr. 35, 274-277.

Sitepu, H. (2003). "Use of Synchrotron Diffraction Data for Describing Crystal Structure and Crystallographic Phase Analysis of R-Phase NiTi Shape Memory Alloy," Textures Microstruct. 35, 185-195.

Sitepu, H. and Brokmeier, H.-G. (2004). "Quantitative Texture Analysis and Phase Fraction of Nickel-Titanium Shape Memory Alloys by Means of Neutron Diffraction," Mater. Sci. Forum 443-444, 267-270.

Sitepu, H. and Brokmeier, H.-G. (2005). "Use of Neutron Diffraction for Describing Texture of Isostatically-Pressed Molybdite Powders," Solid State Phenom. 105, 83-88.

Sitepu, H., Prask, H. J., and Vaudin, M. D. (2001). "Texture characterization in X-ray and neutron powder diffraction data using the generalized spherical-harmonic," Adv. X-Ray Anal. 44, 241-246.

Sitepu, H., Schmahl, W. W., Allafi, J. K., Eggeler, G., Dlouhy, A., Toebbens, D. M., and Tovar, M. B. (2002a). "Neutron diffraction phase analysis during thermal cycling of a Ni-rich NiTi shape memory alloy using the Rietveld method," Scr. Mater. 46, 543-548.

Sitepu, H., Schmahl, W. W., and Stalick, J. K. (2002b). "Correction of intensities for preferred orientation in neutron-diffraction data of NiTi shape-memory alloy using the generalized spherical-harmonic description,” Appl. Phys. A A74, S1719-S1721.

Sitepu, H., O'Connor, B. H., Benmarouane, A., Hansen, T., Ritter, C., and Brokmeier, H.-G. (2004a). "Texture correction in neutron powder diffraction data of molybdite using the generalized spherical harmonic model," Physica B 350, E573-E576.

Sitepu, H., O'Connor, B. H., and Li, D. Y. (2004b). "Deriving the bulk modulus of a single-phase powder from the March preferred orientation parameter," Physica B 350, E577-E580.

Sitepu, H., O'Connor, B. H., and Li, D. (2005a). "Comparative evaluation of the March and generalized spherical harmonic preferred orientation models using X-ray diffraction data for molybdite and calcite powders," J. Appl. Crystallogr. 38, 158-167.

Sitepu, H., Wright, J. P., Hansen, T., Chateigner, D., Brokmeier, H.-G., Ritter, C., and Ohba, T. (2005b). "Combined Synchrotron and Neutron Structural Refinement of R-Phase in $\mathrm{Ti}_{50.75} \cdot \mathrm{Ni}_{47.75} \cdot \mathrm{Fe}_{1.50}$ Shape Memory Alloy," Mater. Sci. Forum 495-497, 255-260.

Stephens, P. W. (1999). "Phenomenological model of anisotropic peak broadening in powder diffraction," J. Appl. Crystallogr. 32, 281-289.

Von Dreele, R. B. (1997). "Quantitative texture analysis by Rietveld refinement," J. Appl. Crystallogr. 30, 517-525.

Wang, F. E., Buehler, W. J., and Pickart, S. J. (1965). "Crystal Structure and a Unique 'Martensitic' Transition of TiNi," J. Appl. Phys. 36, 32323239.

Wenk, H.-R., Cont, L., Xie, Y., Lutterotti, L., Ratschbacher, L., and Richardson, J. (2001). "Rietveld texture analysis of Dabie Shan eclogite from TOF neutron diffraction spectra," J. Appl. Crystallogr. 34, 442-453. 